\title{
Sobre as Resenhas de Kant às Ideias para uma filosofia da história da humanidade, de Herder
}

\author{
Isabel Fragelli \\ Doutoranda em filosofia pela USP
}

Resumo: Pretende-se, neste ensaio, propor uma leitura das Resenhas escritas, por Kant, às Ideias para uma filosofia da história da humanidade, de Herder. A partir de algumas das principais objeções que Kant dirige a essa obra, ser-nos-á possível compreender as diferenças mais fundamentais entre os projetos filosóficos dos dois autores. Veremos, então, que, ao contrário do que pensava Kant (cuja leitura das Ideias é, de fato, muito pouco generosa), Herder também contribuiu, à sua maneira, para uma reconsideração da metafísica.

Palavras-chave: Herder - Kant - Resenhas - filosofia da história
Abstract: It is intended to propose, in this paper, a reading of Kant's Reviews to Herder's Outlines of a philosophy of the history of man. By understanding some of Kant's main objections to this work, we will be able to comprehend the most essential differences between the philosophical projects of both authors. We shall see that, unlike Kant's opinions (whose interpretation of the Outlines is indeed very ungenerous), Herder also contributed, in his way, to the reconsideration of metaphysics.

Keywords: Herder - Kant - Reviews philosophy of history

Em 1784, três anos após o aparecimento da Crítica da Razão Pura, J. G. Herder publicou o primeiro volume de sua obra mais relevante: as Ideias para uma filosofia da bistória da bumanidade. Apesar de nutrir uma admiração declarada por Kant, que fora seu professor na Universidade de Königsberg ${ }^{1}$, Herder jamais escondeu sua visão absolutamente discordante dos preceitos da filosofia transcendental - algo que o aparecimento das Ideias tornou evidente para o público leitor da época. Não por acaso, Kant prontificou-se a contestar as opiniões aí expostas

1. Entre os anos de 1762 e 1764, como mostra John H. Zammito (cf. ZAMMITO, J. H. Kant, Herder: The birth of antbropology. Chicago: The University of Chicago Press, 2002, em especial o capítulo 4). 
por seu ex-pupilo: publicou, já no ano de 1785 , as Resenbas às Ideias para uma filosofia da bistória da bumanidade, de J. G. Herder ${ }^{2}$, nas quais profere duras críticas, tanto ao conteúdo da obra, quando ao estilo - segundo ele, demasiadamente "imaginativo" - de seu autor. Ainda movido pela energia do "despertar do sono dogmático" que lhe fez redigir a primeira Crítica, Kant condena as ambições especulativas dessa filosofia "poética" da história desenvolvida por Herder, acusando-as de serem tão pretensiosas e inadequadas - ou, se preferirmos, tão "dogmáticas" quanto as da metafísica. Herder, obviamente, reagiu de forma bastante negativa a essas críticas, motivo pelo qual decidiu escrever, anos depois, uma Metacrítica da Razão Pura (1799) e a obra Kalligone (1800), nas quais questiona e ataca os princípios mais fundamentais da primeira e da terceira Críticas, respectivamente. Kant, por sua vez, não obstante o tom ácido das Resenhas, encontrou, em seu debate com Herder, algumas boas razões para desenvolver o problema da filosofia da história no interior de seu projeto crítico - o que, entre outras coisas, contribuiu para o surgimento da Crítica do Juízo teleológico.

Uma leitura atenta das Resenhas deverá mostrar que as questões nelas apresentadas extrapolam a querela em torno do problema específico da filosofia da história. Os principais pontos das objeções feitas, por Kant, às Ideias, passam pelo problema da teoria do conhecimento em geral, de modo que a compreensão desses pontos nos permitirá revelar as diferenças mais essenciais entre os projetos filosóficos dos dois autores. Tanto Kant, quanto Herder, acreditam que a abordagem "filosófica" da história não consiste numa mera observação dos fatos empíricos, mas deve propor, para além dessa observação, uma organização teleológica de seu objeto. Como veremos, essa teleologia é fundamentada, por cada um deles, de maneiras distintas - embora ambos concordem que o sentido do percurso histórico não deve ser outro, senão o do aperfeiçoamento (isto é, o da Bildung) de toda a humanidade.

É importante notarmos, ainda, que Herder atribui muito mais importância à apreciação da história, no interior de seu pensamento, do que o faz Kant. No prefácio das Ideias, ele escreve:

2. A primeira e a terceira Resenhas dirigem-se, respectivamente, aos volumes I e II das Ideias; a segunda é, na verdade, uma réplica de Kant a uma resposta escrita, por Reinhold, à sua primeira resenha, na qual este último defendia a obra de Herder das objeções feitas por Kant. 
Já que tudo no mundo tem sua filosofia e sua ciência, não deveria também aquilo que nos diz respeito de forma mais próxima, a história da humanidade inteira e em geral, ter uma filosofia e uma ciência? ${ }^{3}$

Herder não acredita na existência de ideias "a priori", ou de uma "estrutura transcendental da razão"; para ele, o homem "se constitui a si mesmo", inteiramente, ao longo do tempo (e é por isso que a história é "aquilo que nos diz respeito de forma mais próxima"). Notamos, portanto, que a antropologia herderiana depende essencialmente de uma filosofia (ou de uma ciência) da história, por meio da qual possamos compreender as regras que orientam os homens na realização desse seu "processo de formação" (Bildungsprozess).

Visto que a história da humanidade está contida na história do mundo, é "a partir do céu", diz Herder, logo no primeiro capítulo das Ideias, "que deve começar a nossa filosofia da história"4. Os dois primeiros volumes da obra ${ }^{5}$ (aos quais referem-se as Resenhas), tratam praticamente apenas do desenvolvimento da história natural, desde o princípio da organização dos planetas no sistema solar até o início do desenvolvimento cultural da humanidade. Com esse longo e detalhado estudo da evolução natural, Herder pretende encontrar as evidências da existência de uma finalidade (ou de uma intencionalidade) na natureza, a partir da qual ele pudesse compreender, geneticamente, também a história da cultura. Isso nos levaria a admitir que o mundo inteiro foi criado segundo um "plano" - um plano divino, é claro - que deverá ser desvendado pelo filósofo. Ainda no prefácio da obra, Herder perguntase: se "Deus organizou tudo na natureza segundo medida, número e peso", então

como (...), no que diz respeito à destinação e à disposição de nosso gênero em geral, teria ele deixado escapar a sua sabedoria e sua bondade e não possuir, aqui, nenhum plano? ${ }^{6}$

3. HERDER, J. G. Ideen zur Pbilosopbie der Geschicbte der Menschbeit. In: Jobann Gottfried Herder - Werke, Bd. 6. Frankfurt am Main: Deutscher Klassiker Verlag, 1989, p. 14 .

4. Idem, p. 21

5. No total, a obra é composta de XX livros, cujos dez primeiros compõem os dois primeiros volumes.

6. Idem, p. 15. 
Desde as primeiras linhas da obra, o olhar atento do filósofo está à procura de todos os sinais que possam indicar a existência de uma "harmonia universal" de toda a criação. Ele observa, assim, uma série de semelhanças e de "afinidades" entre as estruturas dos seres, bem como uma "proporção", ou uma "economia"7 geral em suas organizações, o que o leva a explicar a passagem de um ser para outro, no interior da cadeia evolutiva, por meio de diversas analogias. $\mathrm{O}$ fato de que a terra ocupa um lugar "intermediário" entre os planetas do sistema solar ${ }^{8}$ "einer der Mittleren Planeten") serve-lhe, por exemplo, para explicar o equilíbrio das forças de formação e destruição que fizeram, dela, um lugar propício para o aparecimento da vida $_{i} \mathrm{e}$, não por acaso, também o homem, o "suprassumo" ("Inbegriff") de todas as criaturas da natureza, é um ser "intermediário" entre duas cadeias distintas de seres ("ein verbindender Mittleglied zweener Welten"9): a dos seres naturais e a das criaturas "superiores", ou espirituais. Por meio desse tipo de procedimento analógico, Herder observa, na natureza, uma tendência para o equilíbrio e para a harmonia, o que lhe permite concebê-la como um grande organismo vivo, que foi criado, por Deus, única e exclusivamente para o surgimento de sua criatura mais elevada: o bomem. Este, por sua vez, foi criado para aperfeiçoar-se - portanto, para atingir a realização máxima de seu próprio conceito (i. e., de sua bumanidade

7. Esse princípio da "economia" é um dos mais fundamentais da filosofia de Herder, especialmente de sua antropologia, o que podemos notar nessa passagem de seu Ensaio sobra a origem da linguagem: "Se o homem tivesse os instintos dos animais, não poderia possuir razão: porque precisamente a forte excitabilidade dos sentidos e o poder avassalador das representações daí decorrentes provocariam a asfixia da frieza que compete à reflexão. / Mas, inversamente, e de acordo com estas mesmas leis que regulam a economia natural das relações em jogo, era necessário que, uma vez desaparecida a sensibilidade animal e o confinamento a um só ponto, sobreviesse uma outra criatura cuja força positiva se exprimisse com maior clareza, num espaço alargado e de acordo com uma organização mais subtil, um ser que já não se limitasse a conhecer, a querer e a agir em independência e liberdade, mas que também soubesse que conhecia, queria e agia. Essa criatura é o homem e a esta disposição global de sua natureza vamos chamar reflexão" (HERDER, J. G. Ensaio sobre a origem da linguagem. Lisboa: Ed. Antígona, 1987, p. 51).

8. Cf. seção II do livro 1 das Ideias: Unsere Erde is einer der Mittleren Planeten. In: HERDER, J. G. Ideen, p. 24.

9. Cf. seção VI do livro 5 das Ideias: HERDER, J. G. Ideen, p. 193. 
(Humanität) ) -, algo que só deverá acontecer quando toda a história humana chegar ao fim, dando lugar ao desenvolvimento de uma nova cadeia de seres "superiores". A existência de uma tal intencionalidade na natureza leva Herder a conceber a história do mundo como uma grande obra da arte (Kunstwerk) divina, mediante uma analogia explícita com a arte humana - isto é, com aquela força criativa que observamos nos homens, por meio da qual eles dão realidade às suas ideias.

Devemos notar que esse "Deus" herderiano, que nada faz sem um propósito, não é, todavia, uma entidade exterior às suas criaturas; ele é, na verdade (tal como o Deus espinosano), a própria natureza:

Para aquele a quem o nome "Natureza", por meio de alguns escritos de nossa época, tornou-se baixo e vazio de sentido, que ele o substitua, para si, pelos daquela toda-poderosa força, bondade e sabedoria, e nomeie, em sua alma, a essência invisível que nenhuma língua terrena é capaz de nomear ${ }^{10}$.

A teleologia desenvolvida, por Herder, não conta com princípios dados a priori, na forma de um plano fixo anterior à ordem do tempo; ao contrário, ela se constrói no próprio processo bistórico, como manifestação de uma força universal viva, que se desenvolve (ao mesmo tempo, livre e necessariamente) na mesma medida em que descobre os caminhos de sua destinação. Isso nos ajuda a compreender por que Herder não faz uma metafísica (dogmática) da história, como julgava Kant, mas sim uma filosofia da história. No início do livro VIII das Ideias, quando se dá a passagem da história natural do homem para a história da cultura, Herder põe uma diferença entre o procedimento metafísico e o procedimento filosófico:

O metafísico encontra, aqui, mais facilidade. Ele estabelece um conceito da alma e desenvolve, a partir dele, aquilo que se deixa desenvolver (...). Para filósofo da história, não pode haver, como fundamento, uma abstração, mas apenas a bistória mesma ${ }^{11}$.

Ora, se o sentido do percurso histórico não é dado por nenhum postulado da razão, então ele terá que ser descoberto, pelo filósofo, a

\footnotetext{
10. Idem, p. 17.

11. Idem, p. 286.
} 
partir da observação de seu objeto (isto é, dos fatos históricos) ${ }^{12}$. Isso explica por que Herder, ao recontar esse percurso, empenha-se tanto em compreender detalhadamente cada momento histórico na sua especificidade, ou na sua particularidade. O particular não é, para ele, apenas um meio para um fim maior; ele é, ao mesmo tempo, meio para um fim último $e$ fim em si mesmo (tal como uma mônada leibniziana ${ }^{13}$. Ao longo de toda a narrativa filosófica das Ideias, o sentido vai sendo, assim, construído (ou reconstruído) passo a passo, momento após momento, numa trajetória que aponta para o infinito.

Não é difícil entendermos, com base no que foi dito até aqui, os motivos pelos quais as Ideias não agradaram a Kant. As críticas que ele apresenta, nas Resenhas, dirigem-se tanto ao conteúdo da obra, quanto à sua forma de exposição e à sua linguagem. No final da primeira Resenba, ele diz:

É de se esperar que, na continuação da obra, na qual terá um solo firme sob os pés, nosso espirituoso autor deva pôr seu gênio vivaz sob alguma constrição, e que a filosofia, cuja tarefa é mais a de podar os ramos abundantes, do que a de deixá-los crescer, conduza-o na conclusão de sua empreitada, não por sugestões, mas por conceitos determinados; não por conjecturas, mas por leis observadas; não por meio de uma imaginação inspirada (befligelten Einbildungskraft), seja pela metafísica, seja pelas sensações, mas de uma razão que seja expansiva em seu desígnio, porém cautelosa na execução ${ }^{14}$.

Como vemos, Kant condena Herder por fazer um uso descomedido da imaginação e por precipitar-se em suas conclusões teóricas. É por isso que um dos principais argumentos das objeções apresentadas, nas Resenbas, diz respeito ao uso das as analogias, nas Ideias. Como dissemos mais acima, é verdade que Herder adota o procedimento analógico como o principal instrumento especulativo de sua filosofia da

12. Cf. p. 9 deste artigo, a respeito da maneira segundo a qual Herder concebia a relação entre sujeito e objeto.

13. Convém mencionarmos, aqui, a obra Também uma filosofia da bistória para a formação da bumanidade, na qual Herder apresenta essa relação entre o particular e o universal na história de forma ainda mais expressiva do que nas Ideias.

14. KANT, I. Rezension zu Johann Gottfried Herders Ideen zur Philosophie der Geschichte der Menschheit. In: KANT, I. Scbriften zur Antbropologie, Geschichtsphilosopbie, Politik und Pädagogik. Frankfurt am Main: Ed. Suhrkamp, 1977, vol. 2, p. 793. 
história, com o qual ele opera a passagem do desconhecido para o conhecido, tanto no campo do sensível, quanto no campo do suprassensível, e, ainda, de um para o outro. Um dos exemplos mencionados, por Kant, do uso "ilegítimo" desse procedimento refere-se à passagem das Ideias, na qual Herder infere, a partir do fato de que o homem possui o andar ereto, o fato dele ter desenvolvido a razão:

Querer determinar qual organização da cabeça, externamente em sua figura e internamente quanto ao cérebro, está necessariamente ligada à predisposição para o andar ereto ${ }_{i} \mathrm{e}$, mais ainda, como uma organização voltada apenas para este fim contém o fundamento da faculdade da razão, (...) - isso evidentemente extrapola toda razão humana, queira ela seguir tateando pelas diretrizes da fisiologia, ou voar por aquelas da metafísica ${ }^{15}$.

Evidentemente, o autor da Crítica da Razão Pura não poderia aceitar esse tipo de "salto" entre o universo empírico e o universo inteligível, tão característico do raciocínio analógico. Em suas palavras: "nenhuma analogia pode preencher essa lacuna incomensurável que há entre o contingente e o necessário"16, de modo que a razão precisa ser extremamente cuidadosa, se quiser empregar esse instrumento para fins especulativos. Na parte final da Dialética Transcendental da primeira Crítica, dedicada ao problema da teologia física, notamos que Kant também recorre à analogia para explicar a existência de uma fi-

15. Idem, Ibidem. Uma das descrições mais belas desse trabalho sintético da analogia, por meio do qual Herder relaciona a história natural com a história da cultura, encontra-se no ensaio Também uma filosofia da bistória para a formação da bumanidade: "Repara nesta torrente [de água] que avança! Vês como nasceu de uma pequena fonte, como cresceu, como arranca aqui um pedaço de terra que acaba por depositar acolá, como serpenteia para furar mais fundo e depois engrossar? (...) E se fosse também assim com o gênero bumano? Ou repara naquela árvore que não para de crescer! Naquele homem que se agiganta! Tem que passar por diferentes idades, sempre em manifesta progressão contínua, sempre num esforço de continuidade! Entre cada idade parece haver momentos de repouso, revoluções, transformações! (...) É assim que fala a analogia da Natureza, imagem de Deus discursando em todas as obras! E evidentemente também no gênero humano!" (HERDER, J. G. Também uma filosofia da bistória para a formação da bumanidade. Lisboa: Ed. Antígona, 1995, p. 45, grifo meu).

16. Idem, p. 795. 
nalidade na natureza - porém de uma maneira bastante distinta da de Herder. A "prova físico-teológica" da existência de Deus desenvolvida, nessa seção da obra, mostra-nos de que maneira a razão procura, a partir da experiência sensível do particular, os fundamentos da existência de um Ser supremo, criador de todas as coisas. Nesse caso, ao observar "por toda a parte no mundo", diversos "sinais evidentes" de um "ordenamento conforme a fins", a razão julga que a natureza foi criada por uma "inteligência que atua mediante a liberdade". Assim como Herder, também Kant insere, aqui, uma analogia entre o trabalho desta inteligência e arte humana:

A razão conclui que a natureza deve ter precisamente por princípio (...) uma inteligência e uma vontade, fazendo derivar ainda de uma outra arte, embora de uma arte sobre-humana, a possibilidade interna da natureza livremente operante ${ }^{17}$.

Todavia, a crítica já havia mostrado que a razão não pode demonstrar a existência de um Ser supremo (visto que, para isso, ela precisaria ser capaz de inferir uma causa inteligível a partir da experiência sensível):

A ideia transcendental de um ser originário necessário e absolutamente suficiente é tão hiperbolicamente grande, tão elevada acima de tudo o que é empírico e sempre condicionado, que, por um lado, não só não poderá nunca encontrar na experiência matéria suficiente para preencher tal conceito, mas também, por outro lado, sempre se anda às apalpadelas entre o condicionado e o incondicionado, do qual nenhuma lei de síntese empírica nos dará jamais um exemplo, nem o menor indício ${ }^{18}$.

Por esse motivo, a "prova físico-teológica" não admite um uso "constitutivo" da analogia. A razão deve (por uma necessidade prática) considerar o mundo "como se" ele tivesse sido criado segundo princípios racionais, ou segundo uma intenção, tal como o é uma "obra de arte"; mas ela não pode pretender que essa consideração possua um caráter determinante e possa equivaler a uma verdade científica. A aplicação da analogia é, portanto, nesse caso, meramente "regulativa": ela serve

17. KANT, I. Crítica da Razão Pura. Lisboa: Ed. Fundação Calouste Gulbenkian, 2001, p. 521

18. Idem, p. 518. 
para "dirigir o entendimento para um certo fim", mas suas conclusões ficam "totalmente fora dos limites da experiência possível"19 (portanto, daqueles do conhecimento).

Uma outra objeção central que Kant expõe, em suas Resenbas, diz respeito ao conceito de força $(\mathrm{Kraft})$ presente nas Ideias. Este conceito é um dos mais essenciais da teoria do conhecimento herderiana, pois é por meio dele que Herder compreende a identidade entre o sensível e o suprassensível - algo que, por si só, já denuncia as diferenças entre os dois autores. Em oposição aos princípios da filosofia crítica, Herder não acredita que a estrutura da razão possa ser "transcendental", isto é, que ela possa existir independentemente do corpo. Ele afirma que a razão não é nenhum elemento atemporal, dotado de uma estrutura fixa, tal como um "autômato inato", mas algo que se constrói e se transforma a partir da experiência que o homem estabelece com os objetos, ou seja: algo adquirido pelo homem, mediante a aprendizagem e o exercício:

Isto é a razão: a obra contínua da formação (Bildung) da vida humana ${ }^{20}$.

Em sua Metacrítica da Razão Pura (1799), Herder investe duramente contra a tese dualista que ele encontra no pensamento de Kant, ao mesmo tempo em que desenvolve alguns dos princípios de sua própria filosofia do conhecimento. A respeito dos conhecimentos a priori, ele diz não saber de onde vêm, já que não vêm de nenhuma experiência, e tampouco entende que o fato de serem a priori tem algo a ver com o fato de serem universais e necessários: "o conceito de uma prioridade anterior a toda experiência", ele diz, "não pode dar universalidade e necessidade a conhecimento algum, se este já não for, segundo sua própria natureza, universal e necessário"21. Essa ideia de algo a priori deve, portanto, ser "deixada de lado": a experiência é, na verdade, o meio pelo qual o objeto "nos ensina a conhecer" e, por isso, a razão humana cresce e constrói-se, na mesma medida em que apreende os objetos do mundo. A relação entre sujeito e objeto implicada no conhecimento é uma relação viva de troca, por meio

19. Idem, p. 534.

20. HERDER, J. G. Ideen, p. 144.

21. HERDER, J. G. Eine Metakritik zur Kritik der reinen Vernunft. In: Jobann Gottfried Herder - Werke, Bd. 8. Frankfurt am Main: Deutscher Klassiker Verlag, 1998, p. 334 . 
da qual a razão se transforma e, ao longo do tempo, abandona certas formas, cria outras, sem jamais encontrar uma forma encerrada e definitiva para si.

Em um ensaio anterior às Ideias, intitulado Sobre o conbecer e o sentir da alma bumana (publicado em 1778), Herder já se manifestava contra o dualismo, ao questionar a ideia de que a faculdade de conbecer $^{22}$ e aquela do sentir são faculdades distintas na alma humana. Sua intenção, neste ensaio, é a de afirmar a natureza essencialmente bíbrida do homem, procurando mostrar que nem a tese idealista, nem a tese materialista podem servir de base para uma filosofia verdadeiramente "saudável":

Já foi longa e, certamente, será eterna a disputa em que permanecem dois partidos: um que, na doutrina da alma, tudo deriva a partir do interior, e outro que, nela, tudo deriva a partir do exterior. Quando aqueles lançam-se aos mais elevados excessos, então há idealistas; quando estes, então há materialistas; a filosofia saudável oscila (schwebt) - assim como nós somos seres manifestamente mistos entre os dois e utiliza-se de ambos ${ }^{23}$.

A fim de explicar a interação entre as duas referidas faculdades, Herder introduz seu conceito de força. A sensibilidade e o pensamento são, para ele, duas forças indissociáveis ${ }^{24}$ que fazem do ser humano um organismo vivo, uno e indivisível. Em sentido geral, essaforça pode ser compreendida como uma espécie de poder vital, ou como uma atividade geral de auto-realização e de auto-organização, tanto da matéria, quanto do espírito (os quais se diferenciam entre si apenas devido ao grau de organização de cada um, sendo o da matéria menor que o do espírito). O indivíduo inteiro é, assim, um conjunto de forças

22. Compreendida, aqui, como uma atividade puramente espiritual.

23. HERDER, J. G. Vom Erkennen und Empfinden der menscbilichen Seele. In: Jobann Gottfried Herder - Werke, Bd. 4. Frankfurt am Main: Deutscher Klassiker Verlag, 1994, p. 1086. O trecho citado é da primeira redação da obra, de 1774, e consta no posfácio da mencionada edição.

24. Na mesma edição de 1774, ele escreve: "Nós pesquisaremos a influência recíproca de ambas as forças (Kräfte) - a da sensibilidade e a do pensamento -, e veremos que nada se pode nem somente com uma, nem somente com outra". Idem, Ibidem. 
orgânicas que atuam (ou que se realizam) no mundo: "Força: seria: eu penso, logo eu atuo no universo logo, eu sou corpo" 25 .

Nas Ideias, Herder expande a sua teoria das forças, afirmando que elas constituem não apenas o homem e suas faculdades, mas todas as coisas do mundo. De acordo com o que vimos mais acima, o DeusNatureza herderiano não é outra coisa, senão uma "força-originária" (Urkraft), compreendida como princípio fundamental de toda criação e de toda transformação da natureza: "O princípio orgânico uno da natureza, que nós chamamos ora formante, ora impulsionante, ora senciente, ora artificioso (künstlicbbauend)" é, no fundo, diz Herder, "apenas uma e a mesma força orgânica"26. Todas as forças particulares (os indivíduos) são partes dessa força originária una, que, ao interagirem constantemente umas com as outras, realizam o processo dinâmico pelo qual se constitui universo.

A passagem do sensível para o inteligível ocorre, portanto, nesse terreno - não exatamente palpável, nem completamente impalpável - da força. Herder, de fato, não define com precisão teórica esse conceito; ele diz apenas que nós podemos ver os efeitos da atuação de forças orgânicas no mundo, e que isso nos dá sinais da existência de uma unidade primordial entre a razão e a natureza ${ }^{27}$. Mesmo que ele não tenha encontrado uma maneira de demonstraro que são essas forças, ele acredita que o fato de termos tantos motivos para suspeitar da existência das mesmas não deve ser simplesmente ignorado pelo filósofo; afinal, uma tal suspeita pode, no mínimo, "suscitar" ideias, ou sugerir caminhos para que, futuramente, se consiga explicá-lo.

Kant, obviamente, jamais aceitaria que a um conceito desse tipo fosse atribuída tamanha importância especulativa. Se não é possível obtermos, por meio da experiência sensível, qualquer certeza a respeito dessas forças, então o conceito das mesmas de nada deve servir

25. HERDER, J. G. Zum Sinn des Gefübls. In: Jobann Gottfried Herder - Werke, Bd. 4, p. 236.

26. HERDER, J. G. Ideen, p. 104.

27. No prefácio das Ideias, Herder escreve: "Eu não acredito que elas [as forças orgânicas] serão consideradas como uma qualitates occultas, pois vemos seus efeitos manifestos diante de nós e eu não soube dar-lhes nenhum nome mais puro e mais preciso. Reservo-me o direito de expandir futuramente o debate sobre isso, bem como sobre outros assuntos que precisei deixar apenas indicados". Idem, p. 17. 
para a razão teórica. Ele afirma, nas Resenhas, que todo esforço de Herder não passa, aqui, de uma tentativa de "explicar aquilo que não se compreende a partir daquilo que se compreende ainda menos" - e isso só pode ser fruto de uma alma que, movida pelo "desespero" de jamais alcançar certos conhecimentos a respeito da natureza, teria sido "forçada a buscá-los no campo fértil de sua força poética" ${ }^{28}$. Em última instância, o que Kant pretende dizer, tanto ao criticar o uso amplo das analogias, quanto ao recusar a validade especulativa desse conceito de força, é que os princípios da "ciência" da história apresentada, nas Ideias, extrapolam totalmente o âmbito da "experiência possível" - isto é, o âmbito no qual o saber científico é legítimo. Ora, diz Kant: "isso é metafísica", e uma metafísica "muito da dogmática, por sinal"29.

Se, por um lado, como pensava Kant, Herder talvez tenha sido um dos responsáveis pela má recepção da filosofia crítica entre seus contemporâneos; por outro, também é provável que as críticas dirigidas, por Kant, a seu ex-aluno tenham contribuído para que este último tenha sido ofuscado, posteriormente, pelo kantismo. Sem tomarmos um partido nessa disputa, convém, aqui, apenas mostrar que a interpretação kantiana das Ideias não reconhece, nelas, a exposição de uma filosofia da história capaz de dispensar a crítica sem, com isso, cair no dogmatismo. Para isso, em primeiro lugar, devemos atentar para a presença da palavra "ideias" no título da obra: ela indica que a intenção de Herder não era a de desenvolver uma filosofia da história encerrada em um sistema definitivo, mas apenas, como ele mesmo diz, a de "deitar, com mãos frágeis, algumas pedras fundamentais de um edifício que apenas os séculos poderiam e iriam concluir ${ }^{\prime \prime 30}$. Herder sabe que a experiência de cada indivíduo é sempre limitada e, portanto, a teoria de cada filósofo é sempre apenas um "ponto de vista", entre tantos outros existentes e possíveis. Ele concebe a filosofia (e, na verdade, o conhecimento em geral) como algo que permanece sempre em aberto - tal como um "edifício" que está sempre em construção. Especialmente no que diz respeito a um objeto como a história - que se transforma incessantemente e que é, para nós, inapreensível em sua totalidade -, o filósofo só pode alcançar a verdade por aproximação. Esse é o motivo

\footnotetext{
28. KANT, I. Schriften, p. 791.

29. Idem, p. 792.

30. HERDER, J. G. Ideen, p. 14.
} 
pelo qual a filosofia que Herder apresenta, nas Ideias, está muito longe de ser aquilo que julgava Kant.

$\mathrm{Na}$ verdade, assim como o projeto filosófico kantiano, também o projeto herderiano sugere uma maneira de repensar a metafísica. Enquanto Kant propõe, para este fim, a sua filosofia crítica, Herder propõe uma filosofia "poetizada" próxima da história e da vida: no primeiro caso, a metafísica deixa de ser ciência para torna-se um produto da razão (a qual é, então, a verdadeira instância provedora de sentido), no segundo, a metafísica exprime a imanência do sentido, o qual, porém, visto que só pode realizar-se no tempo, deve conter sempre, em si, uma abertura. A infinitude desse processo de realização do sentido na história não pode, é claro, ser apreendida no interior daqueles limites da "experiência possível", dos quais falava Kant. Se quisermos, ao menos, nos aproximar dessa infinitude, teremos que encontrar uma linguagem científica menos enrijecida, ou seja, mais aberta e mais criativa - e isso explica toda a poesia da linguagem herderiana. Afinal, não é a analogia um recurso essencialmente poético? Para Herder, não há outra maneira de apreender a infinita multiplicidade de fatos que compõe a história, senão por meio de um pensamento permanentemente capaz de crescer e de transformar-se junto com o seu objeto. Por ser um produto da imaginação, a poesia é o lugar da criação: e essa força criativa Herder exige, não apenas do filósofo, mas igualmente de seu leitor. A intenção de uma obra como as Ideias deve ser muito mais a de "gerar pensamentos" e "suscitar imagens" em seus leitores, esperando que eles possam ajudá-lo a cumprir a tarefa interminável que é a de elaborar uma filosofia da história da humanidade - do que a de apresentar-lhes uma obra acabada e fechada em si mesma. Por esse motivo, devemos reconhecer que, assim como Kant, Herder também foi responsável pelas principais transformações que ocorreram na filosofia alemã de final século XVIII (filosofia esta tão geralmente chamada de "pós-kantiana") - e, nesse sentido, suas obras serão sempre complementares.

\section{Referências Bibliográficas:}

Obras de Herder em alemão:

HERDER, J. G. Eine Metakritik zur Kritik der reinen Vernunft. In: Jobann Gottfried Herder - Werke, Bd. 8. Frankfurt am Main: Deutscher Klassiker Verlag, 1998. 
Isabel Fragelli

Ideen zur Pbilosopbie der Geschicbte der Menschbeit. In: Johann Gottfried Herder - Werke, Bd. 6. Frankfurt am Main: Deutscher Klassiker Verlag, 1989.

Vom Erkennen und Empfinden der menschilichen Seele. In: Jobann Gottfried Herder - Werke, Bd. 4. Frankfurt am Main: Deutscher Klassiker Verlag, 1994.

Zum Sinn des Gefühls. In: Jobann Gottfried Herder - Werke, Bd. 4. Frankfurt am Main: Deutscher Klassiker Verlag, 1994.

Obras de Herder em português:

HERDER, J. G. Ensaio sobre a origem da linguagem. Lisboa: Ed. Antígona, 1987.

Também uma filosofia da bistória para a formação da bumanidade. Lisboa: Ed. Antígona, 1995.

Outras obras:

KANT, I. Crítica da Razão Pura. Lisboa: Ed. Fundação Calouste Gulbenkian, 2001.

Rezension zu Johann Gottfried Herders Ideen zur Philosophie der Geschichte der Menschheit. In: KANT, I. Schriften zur Antbropologie, Gescbichtspbilosopbie, Politik und Pädagogik. Frankfurt am Main: Suhrkamp, 1977, vol. 2.

ZAMMITO, J. H. Kant, Herder: The birth of antbropology. Chicago: University of Chicago Press, 2002. 